\title{
Analysis of Structural Relationship between High-tech Industry Innovation and Three Major Industries
}

\author{
Jianguang Wang ${ }^{1, a}$, Jiayin $\mathrm{Li}^{1, \mathrm{~b}}{ }^{*}$, Shengjun Zhou ${ }^{1, \mathrm{c}}$ \\ ${ }^{1}$ School of Economics, Jilin University, Changchun 130012, China \\ a384702880@qq.com, ${ }^{b}$ 2327798203@qq.com, ${ }^{c}$ 1786567377@qq.com \\ *Corresponding author
}

Keywords: High-tech industry innovation; co-integration test; Granger causality test; VAR equation; three major industries

\begin{abstract}
This paper uses the entropy method to calculate the evaluation value of the innovation level in high-tech industry and the development level in three industries in China. Then the two evaluation values are subjected to the co-integration test and the Granger causality test to further analyze the equilibrium relationship between the level of innovation in the high-tech industry and the level of development in the three major industries. VAR equation is then introduced to establish an autoregressive model. Next the transmission mechanism of the two evaluation values is analyzed and the picture of pulse respond and variance decomposition is used to estimate the strength of interpretation of the transmission mechanism. The results show that there is an equilibrium relationship between the level of innovation in the high-tech industry and the development level of the primary industry and the secondary industry, and the level of innovation in the high-tech industry has a unidirectional conduction effect on the development level of the primary industry and the secondary industry, with certain hysteretic nature. By comparing the picture of pulse respond and other information, it can be further pointed out that the conduction mechanism of the high-tech industry innovation level index to the second industry development level index is the most significant.
\end{abstract}

\section{Introduction}

Industrial innovation capability is the dynamic capability of the industry's scientific and technological innovation activities that influences related industries through conduction and ripple effect, and then drives the entire industrial system to achieve sustainable development of science and technology. The process of industrialization in a country is exactly the process in which the country's industry-level innovation continues to be active. This continuous innovation activity can enhance the efficiency of industrial transformation. Due to the different status of each industry, the innovation strategies and innovation activities of different industries have different effects on the industrial structure. High-tech is the most active factor in the development of modern productive forces. The use of high technology is a revolutionary driving force for industrial upgrading [1]. Further, high-tech industry innovation is the main guiding force for measuring the sustainable development of a country's economy and innovation and entrepreneurship. It not only helps 
countries understand the level of innovation and entrepreneurship, but also helps countries to improve their ability to innovate and direct entrepreneurship [2].

With the continuous deepening of China's reform and opening up, the evaluation of high-tech industry innovation has gradually attracted the attention of scholars. For example, Zhang Youzhi [3] has studied the non-linear relationship between China's financial high-tech industry innovation and economic growth, R\&D expenditure and economic growth based on the smooth transition regression (STR) model. The result was that there was a significant non-linear relationship between China's economic growth and high-tech industry innovation. For another example, Zhu Yun [4] examined the relationship between China's economic growth and high-tech industry innovation by means of co-integration regression analysis, and further pointed out that there was a significant interactive relationship between financial high-tech industry innovation and economic growth. It is a transmission mechanism that pulls and influences each other. Subsequently, Wang Kai et al [5], Zhang Youzhi [6], Ling Jianghuai [7], Guan Xin et al [8] studied China's economic growth and high-tech industry innovation by using VAR model, co-integration test, Granger causality test, and other analytical tools. The long-term equilibrium relationship and the short-term dynamic relationship were analyzed through variance decomposition and impulse response functions. The result was that there was a significant equilibrium relationship between China's economic growth and high-tech industry innovation, and it was accompanied by a certain lag effect.

However, it is worth noting that the conclusions of studies such as Zhang Youzhi [3], Zhu Yun [4], Wang Kai [5], Zhang Youzhi [6], and Ling Jianghuai [7] were mostly based on research in high-tech industry innovation and economic development, but not statistics and analysis of other aspects of high-tech industry innovation. Therefore, on the basis of the above-mentioned scholars' research, this article introduces the relevant indicators of the three major industries and uses entropy method to synthesize the comprehensive index of high-tech industry innovation level and the development level of the three major industries, and then quantifies the level of innovation in high-tech industries and the level of development of the three major industries. Specifically, first of all, it defines the level of innovation in the high-tech industry and the development level of the three major industries, and uses the entropy method to quantify the level of innovation in the high-tech industry and the development level of the three major industries, obtaining evaluation values for each year. Subsequently, after obtaining the evaluation values for each year, the paper uses the co-integration test, ADF test, and other analytical tools to study the long-run equilibrium relationship between the level of innovation in the high-tech industry and the development level of the three major industries. Furthermore, the Granger causality test method is used to study the short-term equilibrium relationship between the development level of the three major industries and the level of high-tech industry innovation. What's more, it adds analysis tools such as VAR to further analyze the conduction relationship between the level of innovation in high-tech industries and the level of development of the three major industries, and then provides theoretical guidance for different industries, such as differentiated management and economic policy formulation.

The contribution of this paper mainly reveals the analysis of other aspects of high-tech industry innovation level, especially the impact of high-tech industry innovation level on the development of primary industry, secondary industry, and tertiary industry, and reveals the coordination and conduction relationship of different systems. The research conclusion is conducive to guiding China's regional economic development and direction of scientific and technological innovation in the future, and provides certain reference value for different levels of scientific and technological innovation in different industries. Further, the research result of this article also provides some enlightenment to the new changes and new adjustments of China's current economic structure. Especially in the context of the tight external environment, the Chinese economy needs urgently to go through in-depth reforms and model remodeling to move toward the mid-to-high level of 
development. Therefore, in the course of economic growth and transformation, it is also necessary to attach great importance to the adjustment of China's industrial structure.

\section{Measuring Evaluation System}

At present, there is no uniform definition of indicators for high-tech industry innovation. Most of the literatures are based on the purpose of their research and define different indicators. For example, Ling Jianghuai [7] studied the relationship between high-tech industry innovation and economic growth, mainly based on per capita GDP as a proxy variable for economic growth, using fiscal high-tech industry innovation and $R \& D$ expenditure as proxy variables for high-tech industry innovation. Zhang Zhengang and other scholars [8] mainly use GDP per capita and R\&D expenditure (STE). Regional research is also mainly based on regional data. For example, Zhang Youzhi et al [9] use the GDP as a dependent variable and use total financial expenditures, financial science and technology allocations, financial science and technology appropriations/total expenditures, total internal expenditures for science and technology activities, and R\&D expenditures as independent variables for empirical analysis when studying the relationship between Jiangsu's financial high-tech industry innovation and economic growth. This paper considers that the research object is mainly located in the high-tech industry innovation level. Therefore, in the process of constructing high-tech industry innovation level indicators, the paper focuses on the relevant indicators of the basic conditions of the high-tech industry in the national database, and constructs 7 Index systems, including full-time equivalents of high-tech industry research and development personnel (10,000 person-years), research and experimental development funds for high-tech industries (100 million yuan), new product development funds for high-tech industries (100 million yuan), and the number of high-tech industry patent applications (pieces), the number of effective invention patents in high-tech industries, the import and export volume of high-tech products (100 million U.S. dollars), and the technical market turnover (100 million yuan). Further, the evaluation index system for the three major industries includes the added value of the primary industry (100 million yuan), the contribution rate of the primary industry to GDP (\%), the pull of the primary industry to the growth of the GDP (percentage point), and the second Industrial added value (100 million yuan), the contribution rate of the secondary industry to GDP (\%), the pull of the secondary industry to the growth of the GDP (percentage point), the added value of tertiary industry (100 million yuan), the contribution rate of the tertiary industry to GDP (\%) and the pull of the tertiary industry to the growth of the GDP (percentage point). The raw data for the paper's research is mainly taken from the annual data from 2000 to 2015. In order to effectively solve the problem of crossover between multiple indicators, this paper uses entropy method [13] to measure the level of innovation in high-tech industries and the level of development of the three major industries [10-12]:

(1)Z-score standardize the original data $X_{i j}$ (this method is based on the standardization of the mean and standard deviation of the original data) and translate the coordinate system $Z_{i j}$ where the normalized data is located by A (A can be determined according to the range of data normalized distribution) to ensure that the data is non-negative. Then get:

$$
Z_{i j}^{\prime}=Z_{i j}+A
$$

(2) Calculate the weight of indicators in the year i under the index j:

$$
p_{i j}=Z_{i j}^{\prime} / \sum_{i=1}^{m} Z_{i j}^{\prime} \text {. }
$$


(3) Calculate the entropy of the indicator j:

$$
e_{j}=-\left(\sum_{i=1}^{m} p_{i j} \ln p_{i j}\right) / \ln m
$$

(4) Calculate the weight of the indicator j:

$$
w_{j}=\left(1-e_{j}\right) / \sum_{j=1}^{n}\left(1-e_{j}\right)
$$

(5) Calculate the evaluation value of high-tech industry innovation:

$$
T C_{i}=\sum_{j=1}^{n} w_{j} p_{i j}
$$

According to the index system and the determined model method, the paper collects the data of China's science and technology board from 2000 to 2015 from the national database, and calculates the level of innovation of high-tech industry in each year, which is defined as the GC Index. In addition, by adding the development levels of the three major industries (defined as FC Index, SC Index and TC Index respectively), it is easy to find that the high-tech industry innovation index and the development index of the three major industries (FC Index, SC Index and TC Index) maintain a certain degree of synchronization, as shown in Table 1 . Therefore, it is necessary to further analyze the high-tech industry innovation index and the development index of the three major industries to study the structural relationship between the high-tech industry innovation level and the development level of the three major industries.

Table 1 Relationship between High-tech Industry Innovation Index and the Development Index of the Three Major Industries

\begin{tabular}{|c|c|c|c|c|}
\hline Year & GC Index & FC Index & SC Index & TC Index \\
\hline 2000 & 0.04535 & 0.053349 & 0.067609 & 0.038854 \\
\hline 2001 & 0.047044 & 0.056207 & 0.046015 & 0.061508 \\
\hline 2002 & 0.047829 & 0.053834 & 0.052806 & 0.059191 \\
\hline 2003 & 0.050146 & 0.044356 & 0.069903 & 0.048123 \\
\hline 2004 & 0.052119 & 0.085629 & 0.060312 & 0.052089 \\
\hline 2005 & 0.054969 & 0.070473 & 0.062421 & 0.06247 \\
\hline 2006 & 0.057719 & 0.066811 & 0.064821 & 0.070009 \\
\hline 2007 & 0.060758 & 0.050374 & 0.070483 & 0.078399 \\
\hline 2008 & 0.064782 & 0.069541 & 0.058711 & 0.065125 \\
\hline 2009 & 0.068993 & 0.059231 & 0.064819 & 0.060509 \\
\hline 2010 & 0.07601 & 0.058864 & 0.078697 & 0.056515 \\
\hline 2011 & 0.080129 & 0.064222 & 0.069066 & 0.064497 \\
\hline 2012 & 0.085696 & 0.070981 & 0.06237 & 0.063311 \\
\hline 2013 & 0.090576 & 0.063224 & 0.061255 & 0.069211 \\
\hline 2014 & 0.057739 & 0.066296 & 0.059943 & 0.07002 \\
\hline 2015 & 0.060142 & 0.066606 & 0.050767 & 0.080167 \\
\hline
\end{tabular}




\section{The Relationship between High-tech Industry Innovation and the Development of Three Major Industries}

According to the economic development theory, there are two relations between the level of innovation in high-tech industries and the level of development of the three major industries: The first relationship is the role of high-tech industry innovation level in driving or influencing the development level of the three major industries; The second relationship is the role of the development level of the three major industries in driving or influencing high-tech industry innovation level. Therefore, in order to test the two possible relationships between the two, the paper first tests the ADF for the high-tech industry innovation index and the three major industries development indices, and then examines the long-term equilibrium characteristics of both by co-integration and then examines the short-term equilibrium characteristics of both by Granger tests. The data is obtained from national database and the sample period is from 2000 to 2015.

\subsection{Stationary test}

The paper uses the ADF method to carry out the unit root test of the high-tech industrial innovation index and the three major industry development indexes respectively. The test results are shown in Table 2. It should be noted that the sequence D_GC and the sequences D_FC, D_SC, and D_TC are the first order differences between the high-tech industry innovation index and the development index of the three major industries, respectively; Among (c, t, k), c, t, k denote the intercept term, time trend term, and maximum lag order in the unit root test respectively. The choice of $\mathrm{k}$ follows the minimum AIC criterion; it determines whether the sequence is stable at the level of 5\%. The software uses EViews8.0 and the same is true below.

Table 2 Sequence stationary test

\begin{tabular}{|c|c|c|c|c|c|c|}
\hline Variable & $\begin{array}{c}\text { Tape of } \\
\text { test }\end{array}$ & T-statistic & $\begin{array}{c}1 \% \\
\text { Significanc } \\
\text { e level }\end{array}$ & $\begin{array}{c}5 \% \\
\text { Significance } \\
\text { level }\end{array}$ & P-values & Conclusion \\
\hline D_GC & $(\mathrm{c}, \mathrm{t}, 1)$ & -3.897637 & -4.800080 & -3.791172 & 0.0423 & stable \\
\hline D_FC & $(\mathrm{c}, \mathrm{t}, 1)$ & -5.716280 & -4.800080 & -3.791172 & 0.0024 & stable \\
\hline D_SC & $(\mathrm{c}, \mathrm{t}, 1)$ & -6.731821 & -4.886426 & -3.828975 & 0.0007 & stable \\
\hline D_TC & $(\mathrm{c}, \mathrm{t}, 1)$ & -3.886046 & -4.800080 & -3.791172 & 0.0431 & stable \\
\hline
\end{tabular}

The test results shown in Table 2 indicate that there is no unit root at the $5 \%$ significance level for the one-valued differential sequences D_GC and D_TC (P values less than 0.05 ), indicating that the monovalent differential sequences D_GC and D_TC are stable and monovalent. There are no unit roots at the significant levels of $1 \%$ and $5 \%$ for the differential sequences D_FC and D_SC, indicating that the monovalent differential sequences D_FC and D_SC are also stable. That is, the high-tech industry innovation index and the development index of the three major industries are first-order unit root series.

\subsection{Co-integration test}

The above has examined that the high-tech industry innovation index and the development index of the three major industries both belong to the first-order unit root series. Therefore, the Johansen co-integration test can be used to further analyze the long-run equilibrium relationship between the sequence D_GC and the sequences D_FC, D_SC, and D_TC [14]. The Johansen co-integration test can select no intercept term, no time trend term, and a first order lag so that the maximum 
eigenvalue and rank test of the Johansen co-integration test can be obtained. The specific results are shown in Table 3.

Table 3 Johansen co-integration

\begin{tabular}{|c|c|c|c|c|c|}
\hline Variable & $\begin{array}{c}\text { Co-integration } \\
\text { relationship }\end{array}$ & Eigenvalue & $\begin{array}{c}\text { Rank } \\
\text { statistics }\end{array}$ & $\begin{array}{c}5 \% \text { critical } \\
\text { value }\end{array}$ & P-values \\
\hline D_GC and & None & 0.560629 & 12.81574 & 12.32090 & 0.0413 \\
\cline { 2 - 6 } D_FC & At most 1 & 0.150761 & 2.124392 & 4.129906 & 0.1710 \\
\hline D_GC and & None $*$ & 0.787381 & 22.19476 & 12.32090 & 0.0008 \\
\cline { 2 - 6 } D_SC & At most 1 & 0.147035 & 2.067481 & 4.129906 & 0.1774 \\
\hline D_GC and & None & 0.502700 & 11.03546 & 12.32090 & 0.0813 \\
\cline { 2 - 6 } D_TC & At most 1 & 0.139568 & 1.954163 & 4.129906 & 0.1910 \\
\hline
\end{tabular}

From the results shown in Table 3, it is obvious to find that the $\mathrm{P}$ values corresponding to the co-integration tests of the sequences D_GC and D_FC and the sequences D_GC and D_SC are all less than 0.05, indicating that the sequence D_GC and D_FC and the sequences D_GC and D_SC have significant co-integration at $5 \%$ level. As a result, there is a long-term equilibrium relationship between the sequence D_GC and D_FC and the sequence D_GC and D_SC. However, the P values corresponding to the co-integration test of the sequences D_GC and D_TC are all more than 0.05, indicating that there is no significant co-integration relationship between the sequences D_GC and D_TC. This shows that the growth of high-tech industry innovation level and the growth of the first industry and the second industry have better synchronization characteristics and maintain a certain structural relationship. But there is no synchronization feature and no large structural relationship between the growth of high-tech industry innovation and the growth level of the tertiary industry. However, from the co-integration relationship we cannot further find that this structural relationship is a conduction process, so it is necessary to further observe these characteristics from the Granger causality test and VAR pulse diagram [13].

\subsection{Granger causality test}

After obtaining the long-term equilibrium relationship between the sequence D_GC and the sequences D_FC, D_SC, D_TC, the paper further investigates the short-run equilibrium relationship between the sequence D_GC and the sequences D_FC, D_SC, D_TC through the Granger causality test [15]. What needs to be pointed out here is that the lag order of the causality test of the two sequences is set to one order. The specific test results are shown in Table 4.

Table 4 Causality test

\begin{tabular}{|c|c|c|c|c|}
\hline Null hypothesis H0 & $\begin{array}{c}\text { The lagged } \\
\text { order }\end{array}$ & F-statistics & P-values & Conclusion \\
\hline D_FC is not a Granger cause of D_GC & 1 & 3.72584 & 0.0526 & acceptance \\
\hline D_GC is not a Granger cause of D_FC & 1 & 6.30735 & $0.0122 * *$ & rejection \\
\hline D_SC is not a Granger cause of D_GC & 1 & 1.31707 & 0.2680 & acceptance \\
\hline D_GC is not a Granger cause of D_SC & 1 & 20.5843 & $0.0003^{* *}$ & rejection \\
\hline D_TC is not a Granger cause of D_GC & 1 & 0.31821 & 0.5840 & acceptance \\
\hline D_GC is not a Granger cause of D_TC & 1 & 0.93564 & 0.3542 & acceptance \\
\hline
\end{tabular}

Note: Judging whether to accept the null hypothesis at the $5 \%$ level of significance

According to the test results shown in Table 4, it can be concluded that the level of innovation in the high-tech industry is not the Granger cause of the tertiary industry (accepting the null 
hypothesis), indicating that the level of innovation in the high-tech industry does not have a remarkable effect on the development level of the tertiary industry. However, the level of innovation in the high-tech industry is the Granger cause (rejecting the null hypothesis) for the development level of the primary industry and the secondary industry, indicating that the level of innovation in the high-tech industry has remarkable effects on the development level of the primary industry and the secondary industry. Changes in high-tech industry innovation will cause remarkable changes in the development of the primary industry and the secondary industry, but on the contrary, it is incorrect. Combining with Table 4, we can further find that there is a one-way conduction relationship between the level of innovation in the high-tech industry and the development level of the primary industry and the secondary industry, that is, The level of innovation in the high-tech industry has a one-way pulling effect on the development level of the primary industry and the secondary industry, and this one-way conduction has a certain lag.

In order to observe this change of conduction and quantify the size in detail, the paper further uses the VAR (2) model established by EViews8.0 to perform estimation based on the Granger causality test, and then obtains the Cholesky impulse response diagram for each variable unit, as shown from 1(a) to 1(f). From Fig. 1(a) - Fig. 1(b), it can be seen that D_GC has a more striking impact on D_FC, and the maximum impact is concentrated in the 9th phase, and the maximum response is $0.06 \%$; Furthermore, the impact response of D_FC to D_GC is not remarkable and the maximum impact response is only $0.01 \%$. It can be seen that the high-tech industry innovation level index has a remarkable impact on the primary industry development level index $(0.06 \%>0.01 \%)$, indicating that the transmission mechanism of high-tech industry innovation level index to the first industry development level index exists in China's economic development. From Fig. 1(c) - Fig. 1(d), it can be seen that the impact response of D_GC to D_SC is remarkable, and the maximum impact is concentrated in the 9th phase and the maximum response is $0.2 \%$; Furthermore, the impact response of D_SC to D_GC is not remarkable and the maximum impact response is only $0.01 \%$. It can be seen that the high-tech industry innovation level index has the most remarkable impact on the secondary industry development level index $(0.2 \%>0.01 \%)$, indicating that the transmission mechanism of high-tech industry innovation level index to the second industry development level index also exists in the course of China's economic development. From Fig. 1(e) - Fig. 1(f), the impact response of D_GC to D_TC is remarkable, and the maximum impact is concentrated in the 9th phase and the maximum response is $0.03 \%$; Furthermore, the impact response of D_TC to D_GC is not remarkable and the maximum impact response is only $0.01 \%$. It can be seen that the impact of the high-tech industry innovation level index on the tertiary industry development level index is commonly remarkable $(0.03 \%>0.01 \%)$, indicating that the transmission mechanism of high-tech industry innovation level index to the third industry development level index exists in the course of China's economic development.

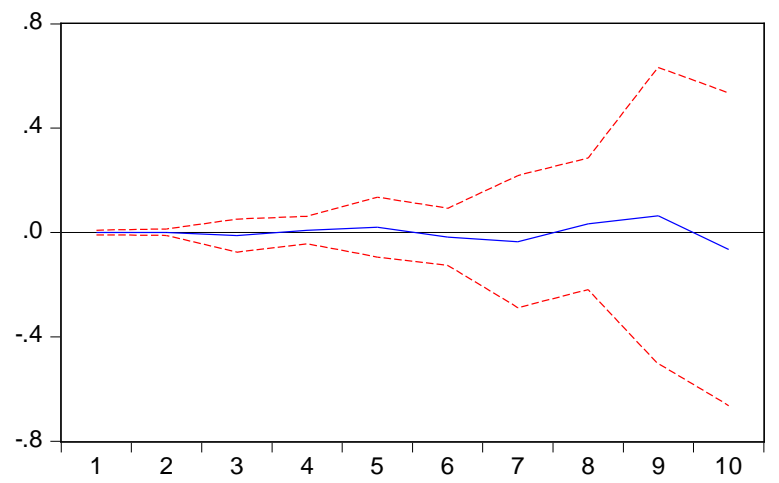

Figure 1(a) Shock response of D_GC to D_FC

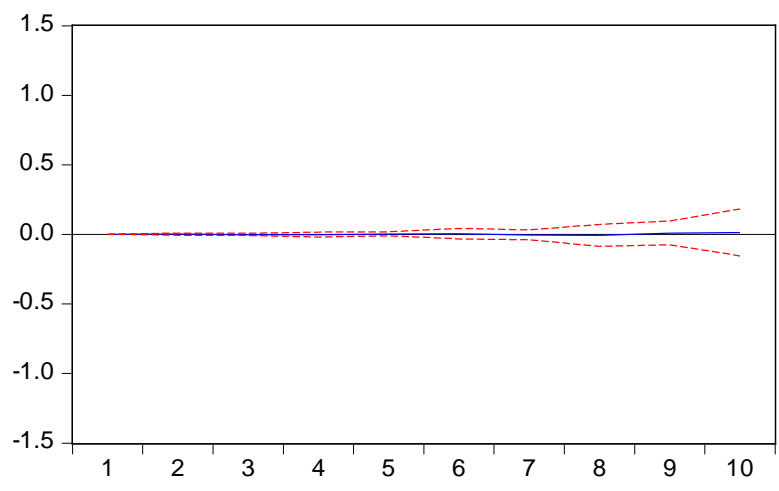

Figure 1(b) Shock response of D_FC to D_GC 

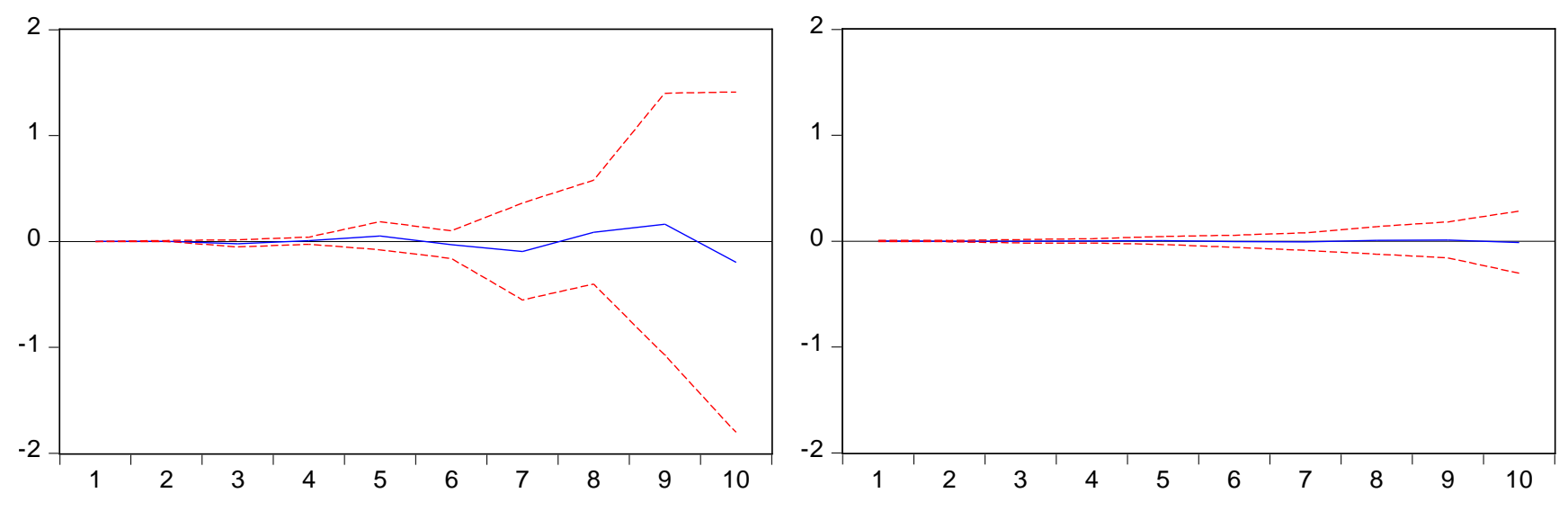

Figure 1(c) Shock response of D_GC to D_SC

Figure 1(c) Shock response of D_SC to D_GC
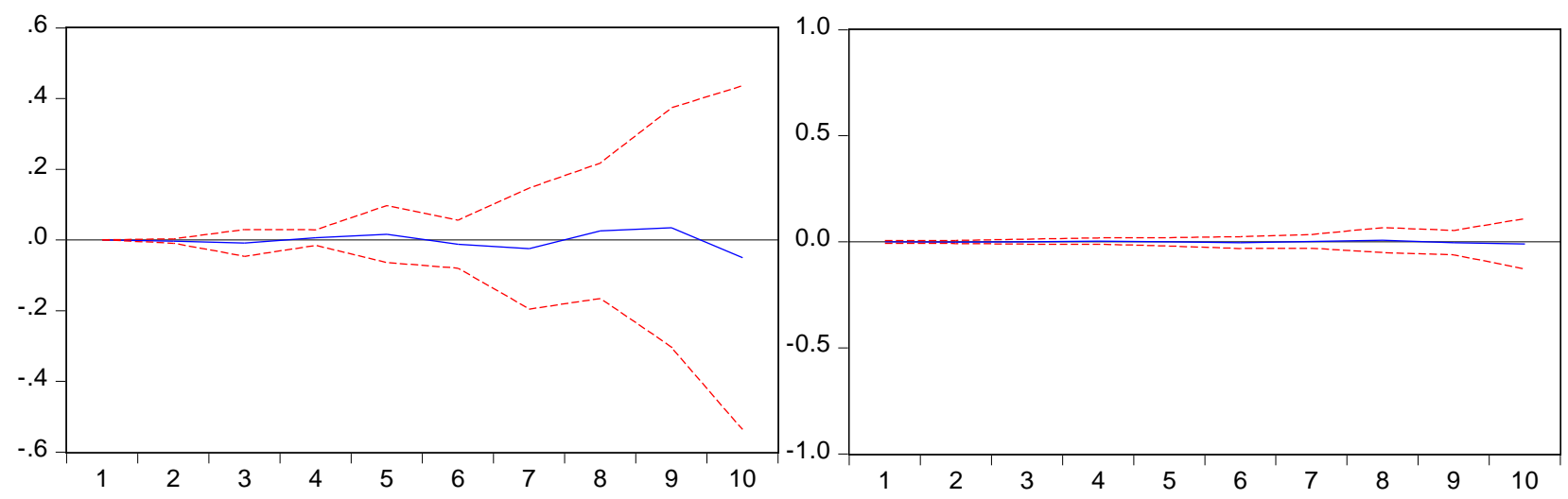

Figure 1(e) Shock response of D_GC to D_TC

Figure 1(f) Shock response of D_TC to D_GC

Comparing the impact response diagram, we can see that the transmission mechanism of the high-tech industry innovation level index to the second industry development level index is the most remarkable. Then the transmission mechanism of the high-tech industry innovation level index to the first industry development level index is more remarkable. Finally, the transmission mechanism of the high-tech industry innovation level index to the tertiary industry development level index is commonly remarkable. This result further proves that the conclusion of causal analysis is correct, but it cannot further analyze the strength or contribution of high-tech industry innovation level index to the three major industry development level index. Therefore, by solving the contribution of error variance, we can understand the relative impact of each factor.

From Table 5, it can be seen that D_GC gradually increases the interpretation of D_FC, D_SC, and D_TC. Among them, D_GC's explanatory power of D_SC is up to $98.96 \%$. D_GC's explanatory power of D_FC is $96.23 \%$. It is also greater than D_GC's explanatory power of D_TC (97.54\%). However, the interpretation of D_GC by the sequences D_FC, D_SC, and D_TC gradually decreases, reaching a minimum of $0.78 \%$. From this perspective, under the transmission mechanism of the high-tech industry innovation level index to the three major industry development level indices, the high-tech industry innovation level index has a greater ability to explain the three major industries development level indexes, especially for the secondary industry, of which the explanatory power is the most remarkable. 
Table 5 Variance decomposition

\begin{tabular}{|c|c|c|c|c|c|c|c|c|c|c|c|c|}
\hline & \multicolumn{2}{|c|}{ D_GC } & \multicolumn{2}{c|}{ D_FC } & \multicolumn{2}{c|}{ D_GC } & \multicolumn{2}{c|}{ D_SC } & \multicolumn{2}{c|}{ D_GC } & \multicolumn{2}{c|}{ D_TC } \\
\hline Period & D_G C & D_FC & D_FC & D_GC & D_GC & D_SC & D_SC & D_GC & D_GC & D_TC & D_TC & D_GC \\
\hline 1 & 100.00 & 0.00 & 99.97 & 0.03 & 96.74 & 3.26 & 100.00 & 0.00 & 99.90 & 0.10 & 100.00 & 0.00 \\
\hline 2 & 98.21 & 1.79 & 99.94 & 0.06 & 96.46 & 3.54 & 91.17 & 8.83 & 98.37 & 1.63 & 85.89 & 14.11 \\
\hline 3 & 99.25 & 0.75 & 69.71 & 30.29 & 98.30 & 1.70 & 18.18 & 81.82 & 99.52 & 0.48 & 45.42 & 54.58 \\
\hline 4 & 98.29 & 1.71 & 61.05 & 38.95 & 98.14 & 1.86 & 20.76 & 79.24 & 98.16 & 1.84 & 37.05 & 62.95 \\
\hline 5 & 99.18 & 0.82 & 35.85 & 64.15 & 98.92 & 1.08 & 4.92 & 95.08 & 99.27 & 0.73 & 16.23 & 83.77 \\
\hline 6 & 98.39 & 1.61 & 27.69 & 72.31 & 98.83 & 1.17 & 5.00 & 95.00 & 98.24 & 1.76 & 12.72 & 87.28 \\
\hline 7 & 99.17 & 0.83 & 14.58 & 85.42 & 99.17 & 0.83 & 1.99 & 98.01 & 99.12 & 0.88 & 6.60 & 93.40 \\
\hline 8 & 98.45 & 1.55 & 10.32 & 89.68 & 99.11 & 0.89 & 1.87 & 98.13 & 98.43 & 1.57 & 5.03 & 94.97 \\
\hline 9 & 99.15 & 0.85 & 5.59 & 94.41 & 99.27 & 0.73 & 1.09 & 98.91 & 98.96 & 1.04 & 3.34 & 96.66 \\
\hline 10 & 98.51 & 1.49 & 3.77 & 96.23 & 99.22 & 0.78 & 1.04 & 98.96 & 98.64 & 1.36 & 2.46 & 97.54 \\
\hline
\end{tabular}

\section{Conclusion}

Based on previous research, this paper studies the relationship between the level of innovation in China's high-tech industry and the level of development of the three industries through analysis tools such as ADF test, co-integration test, Granger causality test, and VAR model. The result is that the increase in the level of innovation in high-tech industries and the growth in the development level of the primary industry and the secondary industry have good synchronization characteristics and maintain a certain structural relationship. However, there is no synchronization feature between the growth of high-tech industry innovation level and the growth of the tertiary industry and there is no significant structural relationship. Based on the Granger causality analysis, there is a one-way conduction relationship between the level of innovation in the high-tech industry and the development level of the primary industry and the secondary industry. That is, the level of innovation in the high-tech industry produces a one-way pulling effect on the development level of the primary industry and the secondary industry, and this unidirectional conduction has a certain lag. The contrast impulse response diagram also shows that the transmission mechanism of the high-tech industry innovation level index to the second industry development level index is the most remarkable, followed by the transmission mechanism of the high-tech industry innovation level index to the first industry development level index is more remarkable, and further demonstrates that the conclusion of causal analysis is correct. Therefore, from a macro perspective, it is necessary to carry out differentiated management of high-tech industry innovations. Different industries can be developed for different industry innovation direction and we should provide more professional guidance for different industries. At the same time, the three major industries should be continuously improved so that the level of three major industries development can provide more resources for high-tech industry innovation.

Finally, it is pointed out that the paper only systematically analyzes the overall status quo, and does not further analyze regional differences. Therefore, in the future research process, we will further explore the influence of China's regional industrial innovation level on the development of different regions' industries through the tool, such as difference coefficient and spatial analysis tools GeoDa-GIS, and then reveal the spatial evolution layout of industrial innovation levels in different regions and the three major industrial development levels. 


\section{References}

[1] Li Sui, Jiang Keshen, High-tech Industry Science and Technology Capability and Optimization and Upgrading of Industrial Structure, J. Science Research Management. 2011, 32 (2) 44-51+66.

[2] Liu Guoxin, Feng Dexiong, Yao Hanjun, et al., Comprehensive Evaluation of Regional Innovation and Entrepreneurial Ability, J. Journal of Wuhan University of Technology (Information \& Management Engineering). 2003, 25 (1) 84-88.

[3] Zhang Youzhi, Research on the Dynamic Relationship between the Investment of Science and Technology and Economic Growth in China, J. Science Research Management. 2014, 35 (9) 58-68.

[4] Zhu Yun, Bi Zhengcao, the Co-Integration Relationship between China's Financial Investment in Science and Technology and Economic Growth, J. Finance \& Economics. 2007 (7) 53-59.

[5] Wang Kai, Pang Zhen, China's financial investment in science and technology and economic growth: 1978-2008, J. Scientific Management Research. 2010, 28(1): 103-111.

[6] Zhang Youzhi, Co-integration test between financial science and technology input and economic growth, J. Science \& Technology Progress and Policy. 2012, 29 (7) 11-16.

[7] Ling Jianghuai, Li Cheng, Li Xi, Research on the Dynamic Equilibrium Relationship between Financial Science and Technology Input and Economic Growth, J. Macroeconomics. 2012 (6) 62-68.

[8] Guan Xin, Qiao Xiaoyong, Meng Qingguo, Research on the Relationship between the Development of High-tech Industry and the Transformation of Economic Development Mode, J. China Population Resources and Environment. 2013, 23 (2) 43-50.

[9] Zhang Youzhi, Investment in Science and Technology and Economic Growth: Nonlinear Relationships with Thresholds, J. Forum on Science and Technology in China. 2014 (5) 32-38.

[10] Zhang Zhengang, Tian Shuai, Chen Zhiming, Research on the Interactive Mechanism between Science and Technology Input and Economic Growth-Based on the Empirical Study of Static and Dynamic Panel Data in the Pearl River Delta Region, J. Scientific Management Research. 2010, 28 (5) 89-93.

[11] Wu Songqiang, Chen Yawen, Zheng Chuiyong, Research on the Relationship between Fiscal Science and Technology Investment and Economic Growth in Jiangsu Province, [J]. 2015, 33 (1) 72-75.

[12] Liu Cui, Study on the Competitiveness of China's Listed Commercial Banks, J. Gansu Finance. 2013 (03) 53-56.

[13] Zhou Zhenglong, Ma Benjiang, Hu Fengying, Optimal Response Scheme Based on Entropy Method and Grey Relational Decision-making, J. Statistics and Decision. 2017 (8) 46-49.

[14] Johansen S. Statistical analysis of co-integration vectors, J. Journal of Economic Dynamics and Control. 1988,12 231-254.

[15] Liang Xiaozhen, Lu Fengbin, Li Dawei, et al., Empirical Research on the Influence of Engineering Construction Standards on China's Economic Growth-Based on Co-Integration Theory, Granger Causality Test and Ridge Regression, J. System Engineering Theory and Practice. 2010, 30 (5) 841-847. 